\title{
O ensino e a transmissão da psicanálise ${ }^{1}$
}

\section{Andréa Hortélio Fernandes}

O ensino e a transmissão da psicanálise fizeram parte dos questionamentos de Freud e Lacan ao longo de suas produções teórico-clínicas, e ainda hoje relançam questões cruciais para a psicanálise, em especial, no que diz respeito a como seria possível transmitir o que há de real na experiência psicanalítica. Cinco lições de psicanálise (1910) é um testemunho disso, por se tratar de publicação escrita das cinco conferências proferidas por Freud na Clark University de Manchester, em Massachusetts. Freud aceita o convite do professor Stanley Hall para proferir palestras durante o $20^{\circ}$ aniversário da universidade, que acontece em agosto de 1909. Numa carta a Jung, Freud comenta que o convite traz a "promessa de uma forte estimulação da psicoterapia entre eles” (FREUD; JUNG, 1906-1914/1992, p. 294). Ele comenta ainda que o convite o honrava muito, e declara que "nós teremos muito o que falar sobre essa viagem e suas consequências para a nossa causa” (Ibid.).

Durante muitos anos, a psicanálise esteve ausente das publicações científicas alemãs, ou mesmo foi objeto de crítica. Freud teve a preocupação de expandir a psicanálise para além do circuito alemão e judaico, e assim demonstrou muita satisfação com a receptividade da parte de Jung, que era suíço e protestante. Jung, além de Ferenczi, acompanha Freud na viagem aos EUA.

Durante sua estadia nos EUA, Freud e seus companheiros de viagem vão pela primeira vez ao cinema, e ao avistarem a Estátua da Liberdade, Freud teria proferido a frase: "Eles não sabem que lhes estamos trazendo a peste!" (FREUD apud LACAN, 1956/1998, p. 404). Lacan afirma que ouviu de Jung esta frase como tendo sido proferida por Freud: "É assim que o dito de Freud a Jung, de cuja boca ouvi, quando ambos convidados da Universidade Clark avistaram o porto de Nova York e a célebre estátua que ilumina o universo" (Ibid.).

Esta frase carrega um chiste, cuja interpretação pode ser articulada às questões relativas ao ensino e à transmissão da psicanálise. Lacan cita Nêmesis, deusa da mitologia grega, que tem o atributo da vingança e era chamada "a inevitável", para dizer que a frase proferida por Freud, com ironia, teria um efeito de chiste "ao apanhar seu autor na cilada". Neste caso, a Nêmesis "só precisou tomá-lo ao pé da letra do seu dito". E aí Lacan adverte: "seria de se temer que ela juntasse a ele

1 Texto apresentado no Seminário Espaço-Escola do Fórum Salvador em 2016. 
uma passagem de volta na primeira classe" (Ibid.). Poderíamos tomar o inevitável como o real enquanto impossível que não cessa de não se escrever e convocar novas associações que vieram a ser elaboradas por Freud ao regressar dos EUA?

Se algo dessa ordem se passou, podemos examinar os traços desde a discussão sobre os possíveis temas das conferências nos EUA. Jung propôs que Freud falasse sobre os sonhos; já Jones recomendou que ele tratasse de assuntos mais amplos. Após refletir, e levando em consideração a carta-convite de Stanley Hall, que lhe solicitava uma exposição de "informações mais generalizadas sobre a psicanálise", Freud considera "que os americanos pudessem considerar pouco prático o assunto dos sonhos" (CHINALLI, 2010, p. 4). Havia muito, Freud já tinha declarado que os sonhos eram a via régia de acesso ao inconsciente; porém, prefere abordar a psicanálise de modo mais "prático" na América, e isso repercutirá nos ecos que a psicanálise terá por lá e está relacionado à transmissão e ao ensino da psicanálise.

Sobre isso é interessante lembrar que Lacan, em 1956, declarara a necessidade de um retorno a Freud "para demonstrar o que a psicanálise não é e, [ ...], buscar o meio de recolocar em vigor aquilo que não cessou de sustentá-la em seu próprio desvio" (LACAN, 1956/1998, p. 404). Retomar aquilo que sustentou a psicanálise no seu próprio desvio estaria atrelado ao tratamento dado ao real pela clínica psicanalítica.

Desde os primórdios da psicanálise, Freud constatou a ineficácia da sugestão na prática analítica. Para tratar o real faz-se necessário manter vivo o discurso analítico, como consta da Carta de Princípios da Internacional dos Fóruns do Campo Lacaniano ${ }^{2}$, para que, de fato, cada analista possa conduzir tratamentos se apoiando e reinventando, com o estilo próprio, as recomendações feitas por Freud (FREUD, 1912/1974).

Nesse sentido, cabe então voltarmos ao texto Sobre o ensino da psicanálise na universidade (1918), no qual é discutida a introdução da psicanálise no currículo médico. O título húngaro do texto é "Deve a psicanálise ser ensinada na universidade?". Segundo nota do editor, este artigo parece ter sido escrito para tratar as reformas na educação médica e, além de Freud, outros autores teriam feito artigos sobre esse tema.

A inclusão da psicanálise no currículo dos estudantes de medicina de Budapeste teria provocado "uma considerável agitação" (FREUD, 1918/1974, p. 215). Freud vai tecer alguns comentários sobre o tema e sustentar certas condições para o ensino e a transmissão da psicanálise na universidade.

"A inclusão da psicanálise no currículo universitário seria, sem dúvida, olhada com satisfação por todo psicanalista", diz Freud (1918/1974, p. 216). Ao mesmo tempo, ele faz a ressalva de que o psicanalista pode prescindir completamente da universidade sem qualquer prejuízo para si mesmo. Freud apresenta o tripé da formação continuada do psicanalista: teoria que pode ser obtida na literatura especializada e nos encontros das sociedades psicanalíticas que dão provas de como

2 http://www.champlacanien.net/public/4/ifCharte.php?language=4\&menu=1 
a formação é continuada. A experiência prática seria adquirida na análise pessoal e nos tratamentos que possam levar a cabo sob supervisão "com membros mais experimentados dessas sociedades" (Ibid., p. 215).

Freud traz uma frase contundente acerca das sociedades de psicanálise, que merece atualização: "o fato de que uma organização desta natureza existe, deve-se, na verdade, à exclusão da psicanálise das universidades” (Ibid., p. 215). Em 1918, e ainda nos dias atuais, a discussão sobre a inclusão da psicanálise na universidade está atrelada a como incorporar a psicanálise à estrutura universitária, tendo o cuidado de manter vivo o discurso analítico em meio aos outros discursos, sobretudo o discurso da universidade e do mestre.

Freud (1918/1974) diz que a psicanálise poderia proporcionar uma preparação para o estudo da psiquiatria. Hoje, podemos afirmar que o fato de a psicanálise ser ensinada na universidade pode colaborar para a despatologização da psiquiatria, pautada pelos manuais de classificação das doenças mentais. Freud já atentava para a evidência de que a psiquiatria era ensinada de forma exclusivamente descritiva, e assim ensinava "o estudante a reconhecer uma série de entidades patológicas, capacitando-o a distinguir quais são as incuráveis e quais são perigosas para a comunidade" (Ibid., p. 218).

O diagnóstico e o tratamento psiquiátrico voltam a ser tema de discussão em 1957, no texto A psicanálise e seu ensino, de Lacan. Ele declara que ao tratar a questão "O que a psicanálise nos ensina, como ensiná-lo?”, não pretendeu dar uma ilustração do seu modo de ensino, mas sim retomar os princípios norteadores da psicanálise. Tal cuidado deve estar presente tanto no ensino como na transmissão da psicanálise na atualidade; se assim não acontecer, corre-se o risco de atingir a psicanálise na sua essência. Portanto, o ensino não deve almejar dar conta da formação teórica excluindo o que é transmitido pela análise pessoal.

Para falar sobre a psicanálise e seu ensino, Lacan enfocará o conceito de sintoma para a psicanálise. O sintoma psicanalisável, seja ele normal ou patológico, distingue-se não apenas do índice diagnóstico, mas de qualquer forma apreensível de pura expressividade, por se sustentar numa estrutura idêntica à estrutura da linguagem. E com isso não nos referimos a uma estrutura a ser situada numa pretensa semiologia generalizada (LACAN, 1957/1998, p. 445).

Sobre a despatologização no tratamento do sintoma pela psicanálise, Freud, em 1918, já chamava atenção de que a aplicação do método da psicanálise "não está de modo algum confinada ao campo dos distúrbios psicológicos, mas estende-se à solução de problemas da arte, da filosofia e da religião" (FREUD, 1918/1974, p. 217), problemas inerentes ao ser falante, portanto. Logo, não é necessário à psicanálise estar circunscrita ao saber da medicina ou da semiologia psiquiátrica. De fato, é na interlocução com as artes, a filosofia e a religião que podemos elencar o 
interesse científico da pesquisa em psicanálise. E isso será defendido por Freud ao escrever o texto $A$ análise leiga:

Não consideramos absolutamente conveniente para a psicanálise ser engolida pela medicina e encontrar seu último repouso num livro de psiquiatria sob a epígrafe "Métodos de Tratamento", juntamente com procedimentos tais como sugestão hipnótica, autossugestão e a persuasão - que, nascidas da nossa ignorância, têm de agradecer a indolência e a covardia da humanidade por seus efeitos efêmeros. Ela merece um destino melhor e espero que o encontre (FREUD, 1926a/1974, p. 280).

Em 1918, a inclusão do ensino da psicanálise por meio de aulas teóricas, "ministradas de forma dogmática e crítica” (FREUD, 1918/1974, p. 216), se mostrou como sendo uma oportunidade muito restrita de capacitar os estudantes de medicina a praticarem a psicanálise. Elas seriam a possibilidade de aprender algo sobre a psicanálise. Para fins de pesquisa, Freud defendeu que os professores deveriam ter acesso a um ambulatório onde seria possível demonstrar que o método e o tratamento psicanalítico coincidem, e daí surgiria uma pesquisa a partir da psicanálise, a partir da clínica, e nesse sentido, o ensino tenderia a uma transmissão a partir da experiência clínica da psicanálise.

Tal ponto faz parte das recomendações aos praticantes da psicanálise desde Freud, quando ele ressaltou que a psicanálise pessoal é, em si, didática. Tanto, que ele não fazia recomendações de leituras de textos psicanalíticos para seus pacientes; em contrapartida sustentava que a experiência pessoal da psicanálise era capaz de transmitir o que há de mais amplo e valioso da literatura psicanalítica (FREUD, 1912/1974). Isso aponta para o que Lacan irá desenvolver ao formular que a psicanálise é em si didática, seja a psicanálise pessoal condição necessária, mas não suficiente para tornar-se analista, seja também a condução de análises sob supervisão.

O ensino da psicanálise volta a ser tema de interesse de Lacan (1970/2003) no texto Alocução sobre o ensino, em que indaga o que acontece ao discurso do analista se cair nas malhas do ensino. Ele diz que está em seus princípios não esperar nada do fato de seu discurso ser tomado como um ensino. Neste ponto ele está, assim como Freud, fazendo uma crítica ao ensino doutrinário da psicanálise, já que a formação do analista é tributária de um saber fazer com o inconsciente, e isso se dá na experiência clínica. Nesta perspectiva, ele vai examinar o lugar ocupado pelo saber nos quatro discursos.

Lacan começa afirmando que "um ensino não significa que com ele vocês tenham aprendido alguma coisa, que dele resulte um saber" (LACAN, 1970/2003, p. 303). Lacan afirma seu espanto "de que a todo instante tenha parecido evidente que o ensino era a transmissão de um saber, tornando-se por horizonte o pêndulo 
que vai e vem entre aquele que ensina e o ensinado" (Ibid., p. 304), aí ele faz menção ao professor e ao aluno.

Quanto ao binômio professor-aluno, Lacan declara que encontramos seu corolário na relação médico-paciente, ativo-passivo, o informativo e o entrópico. Lacan adverte que "pode ser que o ensino seja feito para estabelecer uma barreira ao saber" (Ibid.). Isto já tinha sido destacado por Freud ao reconhecer que a literatura psicanalítica podia fomentar a resistência dos analisantes. Partindo disso, Lacan sustenta que cada um só pode ser ensinado à medida do seu saber; quanto ao professor, Lacan lembra que “já faz um tempão que todos sabem que isso é para eu me instruir" (Ibid., p. 303).

No que diz respeito ao ensino da psicanálise, Lacan questiona o que vem a ser analisado: isso se ensina?

Por meio dos discursos, Lacan vai identificar como o professor pode ser efeito do seu ensino. Ele localiza esse efeito no lugar do $\$$ do discurso do mestre.

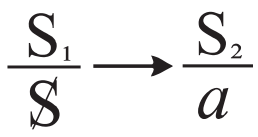

"O professor se produz no nível do sujeito, tal como o articulamos com o significante que o representa para outro significante" (Ibid., p. 305), mas deixa um resto que aponta para um saber não todo que pode circular do professor para o aluno, do aluno para o professor. Esse resto, em vez de despertar o horror de saber, deve causar o desejo de saber.

Contudo, neste discurso, estando o saber no lugar do outro, faz com que o sujeito seja destituído do seu saber pelo saber do outro. É assim que opera o cientificismo e o empirismo: o saber está no pesquisador, no cientista, que tem o saber do sujeito como objeto de pesquisa. Um exemplo seriam as entrevistas dirigidas, que tentam formular perguntas que tornem evidente aquilo que o pesquisador precisa escutar do sujeito entrevistado. De todo modo, o objeto $a$ como resto, como produção deste discurso, revela o impossível da educação, pois o ensino guarda em si algo irredutível, não atingindo a completude, e é o que pode relançar o desejo de saber.

O discurso do mestre, como discurso do inconsciente, revela a operação de alienação ao significante. Ao estar alienado aos significantes do Outro, o sujeito pode ser foracluído pelo saber do mestre e da universidade. Em contraponto, o manejo da transferência convoca o analista a manejar com a suposição de saber a ele dirigida, advertido de que não possui o saber sobre o analisante. A suposição de saber é dirigida ao inconsciente, condição para que uma análise se dê graças ao manejo da transferência suportado pelo desejo do analista. 
O saber, vindo ao lugar do agente, é o quarto de volta que institui o discurso da universidade.

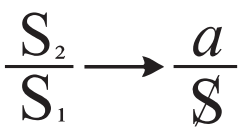

“O saber serve de agente, [...] por se revelar como ensino. O ensino é o saber descaracterizado pelo lugar que ele impera" (Ibid., p. 306), pois para a psicanálise é o não saber que engendra o saber. Isto porque o inconsciente, entendido como um saber não sabido, toma o sintoma como o que convoca sentido. Já no discurso da universidade, o saber é colocado como a Suma, como a totalidade de algo, como o mais alto grau do saber acumulado, o que o faz equivaler à soma e aos gradus universitários.

Nesse discurso o sujeito comparece com sua própria divisão ao se prestar ao serviço do saber como agente; isso promove a divisão subjetiva do sujeito, que faz sintoma. Sintomas tão comumente presentes durante as teses e mestrados, em que o sujeito pode, em alguns casos, ser um compilador de uma teoria. Lacan traz então a frase contundente e atual: "o sono do saber gera monstros, na verdade civilizados" (Ibid., p. 303).

Contrariamente ao discurso do analista no qual o saber inconsciente está no lugar da verdade, no discurso da universidade os significantes-mestres $\left(\mathrm{S}_{1}\right)$ que sustentam o saber universitário estão no lugar da verdade. Lacan conclui que "para chegar ao ensino, o saber deve, por algum aspecto, ser um saber de mestre, ter algum significante-mestre que constitua sua verdade" (Ibid., p. 307).

O discurso muda de figura se o saber é uma produção do "próprio significante-mestre, em posição de ser interrogado pelo sujeito elevado a agente". Estamos então falando do discurso da histérica, $\$ \rightarrow \mathrm{S}_{1} / a \rightarrow \mathrm{S}_{2}$. Lacan diz que "sem dúvida, isso é criar um enigma” (Ibid., p. 307). Por isso a importância da histerização do discurso na entrada em análise e na transmissão da psicanálise. Desta forma, a transmissão da psicanálise pode ir mais além do seu ensino quando parte de questões cruciais colocadas pelo real próprio à clínica.

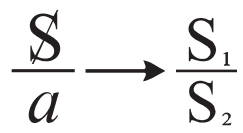

O saber chega ao lugar da verdade pela meia-volta construída pelo discurso, que tem a distribuição oposta à do discurso do mestre sendo, portanto, seu avesso. Temos, então, o discurso do analista. 


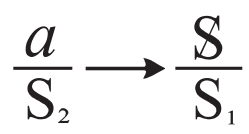

Lacan diz que pela relação do saber com a verdade adquire verdade aquilo que se produz de significantes-mestres no discurso analítico. Ao pedirmos que o analisante associe livremente, fica claro que não se trata de algo a ser ensinado, mas a ser manejado pela transferência.

Lacan destaca que o "saber faz a verdade" do discurso do analista, e nem por isso a análise como didática dispensa o analista da hipoteca do saber, uma dívida para com o saber inconsciente e para com a psicanálise. Isto pode ser articulado à formação continuada do psicanalista que só se autoriza por si mesmo, mas não sem os outros, não sem a exposição daquilo que faz ao conduzir análises e quando se dedica à elaboração continuada da teoria psicanalítica a partir das questões trazidas pela clínica.

A experiência do passe é primorosa quanto a isto, pois ela seria em si uma tentativa de transmissão na qual "o passante toma seu próprio caso clínico, seu percurso de análise, como lugar que abriga um saber. Isso é o que o anima a trabalhar sobre sua própria experiência” (NOMINÉ, 2016, p. 43). Tal fato mostra a aposta que Lacan fez no passe, pois ao longo de sua obra ele se questionou sobre o ensino e a transmissão da psicanálise como também no que o passe poderia contribuir para fazer avançar a psicanálise.

Para Lacan, cada psicanalista é forçado a reinventar a psicanálise, e isso toca o desejo de psicanálise tal como foi discutido no Encontro Internacional da Escola de Psicanálise dos Fóruns do Campo Lacaniano em Medellín, em 2016. Nesta perspectiva é muito pertinente a afirmação de Nominé de que é preciso "que cada psicanalista reinvente o modo com o qual a psicanálise pode durar a partir do que conseguiu tirar (de sua experiência) por ter sido, por um tempo psicanalisante" (LACAN apud NOMINÉ, 2016, p. 43). É importante retomar a necessidade de a psicanálise em intensão e em extensão funcionar como "um casal inseparável" Un couple inséparable - título do trabalho de Martine Mènes, em Medellín, sobre a formação do analista.

Nominé retoma este ponto ao abordar o fato de que, em certa época, entre os analistas se defendia que a transferência de trabalho seria o desenlace da transferência. A transferência de trabalho Nominé define como:

[...] o que se transmite ao final da cura é o trabalho e se transmite do analista para o analisante que, ao final da cura, já não necessita da presença do analista para continuar seu trabalho de analisante. [...]. Trata-se, antes, de se apoiar em seu próprio trabalho fundado na transferência estabelecida em seu percurso na análise (NOMINÉ, 2016, p. 44). 
Para concluir, a retomada por Lacan da frase em que Freud afirmou que levava a peste aos americanos e poderia estar trazendo-a consigo na bagagem de volta, sem o saber, pode ser associada ao ensino e à transmissão da psicanálise. Freud, ao concordar que os americanos poderiam julgar menos "prático" o tema dos sonhos, promoveu certo abalo no seu desejo de psicanálise, o que culminou com uma tentativa de passar um tom tranquilizador do inconsciente. Mais tarde, ele vai reconsiderar a aceitação de suas ideias nos EUA, numa entrevista concedida ao jornalista George Viereck:

Tenho receio da minha popularidade nos EUA. O interesse americano pela psicanálise não se aprofunda. A popularização leva à aceitação superficial sem estudo sério... A América foi o primeiro país a reconhecer-me oficialmente. A Clark University concedeu-me um diploma honorário quando eu ainda era ignorado na Europa. Entretanto, a América fez poucas contribuições originais à psicanálise (FREUD, 1926b/s./d.).

Lacan não cede ao seu desejo de psicanálise e conclui o texto Alocução sobre o ensino dizendo que "ao se oferecer ao ensino, o discurso psicanalítico leva o psicanalista à posição do psicanalisante, isto é, a não produzir nada que possa dominar, malgrado a aparência, a não ser a título de sintoma” (LACAN, 1970/2003, p. 310). É desta forma que ele pode transmitir algo sustentado pelo real do sintoma próprio à experiência da psicanálise como atesta o discurso da histérica.

\section{Referências bibliográficas}

CARTA DE PRINCÍPIOS DA INTERNACIONAL DOS FÓRUNS DO CAMPO LACANIANO. Disponível em: http://www.champlacanien.net/public/4/ ifCharte.php?language $=4 \&$ menu $=1$. Acesso em: 10 abril 2016.

CHINALLI, M. A chegada da peste: cem anos da viagem de Freud aos EUA (19092009). Arquivo Maravi: Revista Digital de Estudos Judaicos da UFMG. Belo Horizonte, v. 4, n. 7, out. 2010, p. 4.

FREUD, S.; JUNG, C. (1906-1914) Correspondance 1906-1914. Paris: Gallimard, 1992.

FREUD, S. (1912) Recomendações aos médicos que exercem a psicanálise. In: Edição Standard Brasileira das Obras Psicológicas Completas de Sigmund Freud. Rio de Janeiro: Imago, 1974, v. 12.

- (1918) Sobre o ensino da psicanálise na universidade. In: Edição Standard Brasileira das Obras Psicológicas Completas de Sigmund Freud. Rio de Janeiro: Imago, 1974, v. 17. 
. (1926a) A análise leiga. In: Edição Standard Brasileira das Obras Psicológicas Completas de Sigmund Freud. Rio de Janeiro: Imago, 1974, v. 20.

(1926b) O valor da vida - entrevista rara de Freud. Disponível em: http://www.sedes.org.br/Departamentos/Formacao_Psicanalise/ActoFalho9/ entrevista_com_freude.htm, s/d. Acesso em: 10 abril 2016.

LACAN, J. (1956) A coisa freudiana. In: Escritos. Rio de Janeiro: Jorge Zahar Ed., 1998.

. (1957) A psicanálise e seu ensino. In: Escritos. Rio de Janeiro: Jorge Zahar Ed., 1998.

. (1964) Ato de fundação. In: Outros escritos. Rio de Janeiro: Jorge Zahar Ed., 1998.

. (1970) Alocução sobre o ensino. In: Outros escritos. Rio de Janeiro: Jorge Zahar Ed., 1998.

NOMINÉ, B. Desenlace da transferência. Stylus: Revista de Psicanálise, n. 32. Rio de Janeiro: Associação Fóruns do Campo Lacaniano, 2016, pp. 37-45.

\section{O ensino e a transmissão da psicanálise The teaching and transmission of psychoanalysis}

\section{resumo}

O artigo examina o ensino e a transmissão da psicanálise partindo da visita de Freud a Clark University e as impressões dele do interesse americano pela psicanálise. Discute o ensino da psicanálise na universidade a partir do texto de Freud sobre o ensino da psicanálise na universidade de 1918 e atualiza o debate com Lacan, tomando o texto Alocução sobre o ensino como chave de leitura. A especificidade da psicanálise é ressaltada pelo lugar que o saber ocupa nos quatro discursos tendo por perspectiva defender que a transmissão da psicanálise tem por suporte o real próprio à experiência da psicanálise tal qual a posição do objeto a no discurso da histérica.

\section{palavras-chave:}

Psicanálise; ensino; transmissão; saber; real. 


\section{abstract}

The article examines the teaching and transmission of psychoanalysis as of Freud's visit to Clark University and his impressions on the American interest in psychoanalysis. The text discusses the teaching of psychoanalysis in the university from Freud's text on the teaching of psychoanalysis at the University of 1918 and updates the debate with Lacan, taking the text Address on teaching as a key to reading. The specificity of psychoanalysis is emphasized by the place that knowledge occupies in the four discourses, whose perspective is to defend that the transmission of psychoanalysis is supported by the real itself to the experience of psychoanalysis, such as the position of the object $a$ in the discourse of the hysteric.

\section{keywords:}

Psychoanalysis; teaching; transmission; knowledge; real.

\section{Recebido:}

$24 / 05 / 2017$

\section{Aprovado:}

02/07/2017 